\title{
Koch-Haaf reaction of adamantanols in an acid- tolerant hastelloy-made microreactor
}

\author{
Takahide Fukuyama*, Yu Mukai and Ilhyong Ryu*
}

\section{Letter}

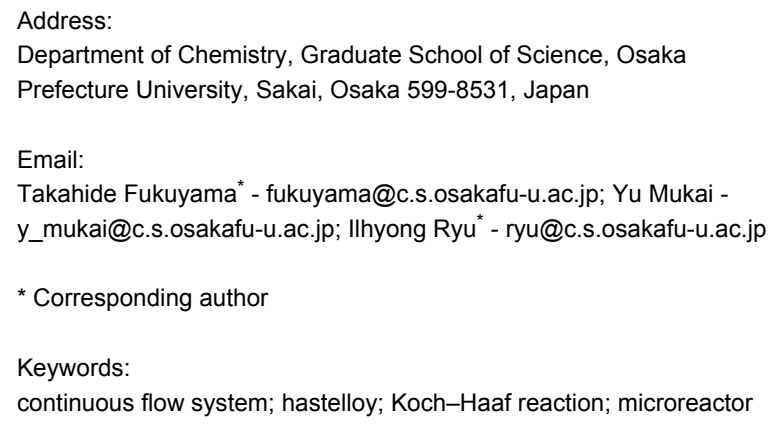

\begin{abstract}
The Koch-Haaf reaction of adamantanols was successfully carried out in a microflow system at room temperature. By combining an acid-tolerant hastelloy-made micromixer, a PTFE tube, and a hastelloy-made microextraction unit, a packaged reaction-toworkup system was developed. By means of the present system, the multigram scale synthesis of 1-adamantanecarboxylic acid was achieved in ca. one hour operation.
\end{abstract}

\section{Introduction}

The recent evolution of microreactor technology has allowed synthetic chemists to use this precisely sophisticated reaction apparatus in place of the well-established glassware batch flask [1-10]. Microreactors are expected to have a significant impact on chemical synthesis and production because of their many advantageous characteristics, such as highly efficient mixing, efficient heat transfer ability, precise control over the residence time, and high operational safety. We have studied and developed practical organic syntheses using flow microreactors, and we have reported thus far examples of Pd-catalyzed coupling reactions [11-13], radical reactions [14-16], and photoreactions [17-21].
Carbonylation reactions are a powerful tool for the introduction of carbon monoxide into organic molecules, and we also reported that Pd-catalyzed carbonylation [13] and radical carbonylation [16] could be successfully carried out in a continuous microflow system with higher efficiency than in a batch autoclave system. In this study, we focused on the carbonylation of carbocation intermediates carried out in a continuous microflow system [22-24]. The Koch-Haaf reaction [25], that is the carbonylation of alcohols or olefins with formic acid in the presence of a strong acid, is an important reaction for the preparation of carboxylic acids, which are widely used in organic synthesis [26-31]. Since the Koch-Haaf reaction is 
highly exothermic, the reaction is typically carried out at controlled temperature by means of a cooling bath, such as an ice bath, and with carefully controlled slow addition of reagents through an addition funnel. The temperature control causes a serious problem especially for large scale synthesis. Herein, we report that the Koch-Haaf reaction in a microflow reactor can be carried out at room temperature without any cooling equipment. The employed hastelloy-made microreactor system was compatible with corrosive (strongly acidic) conditions and confirmed for gram scale $(7.1 \mathrm{~g})$ synthesis of 1-adamantanecarboxylic acid in ca. $1 \mathrm{~h}$ operation.

\section{Results and Discussion}

The carbonylation reaction of 1-adamantanol (1a) was investigated in a microflow system as a model reaction. Since the Koch-Haaf reaction requires the use of concentrated sulfuric acid, an acid-tolerant system is essential. For this study, we employed a combination of a hastelloy-made micromixer (MiChS, $\beta-150 \mathrm{H})$ having $150 \mu \mathrm{m}$ reactant inlet holes and $200 \mu \mathrm{m} \times 300 \mu \mathrm{m}$ channels (Figure 1), and a PTFE tube (1.0 mm i.d. $\times 3 \mathrm{~m}$, inner volume: $2.36 \mathrm{~mL}$ ) as a residence time unit. To this reactor system, a hastelloy-made microextraction unit (a flow-workup system) was attached (Figure 2 and Figure 3). The microextraction unit has three inlets and one outlet (channel size: $1 \mathrm{~mm}$ i.d. $\times 14 \mathrm{~cm}$ ). The reaction mixture was mixed at $\mathrm{T}$-shaped junctions with $\mathrm{Et}_{2} \mathrm{O}$ and water, and a biphasic mixture was collected from the outlet.

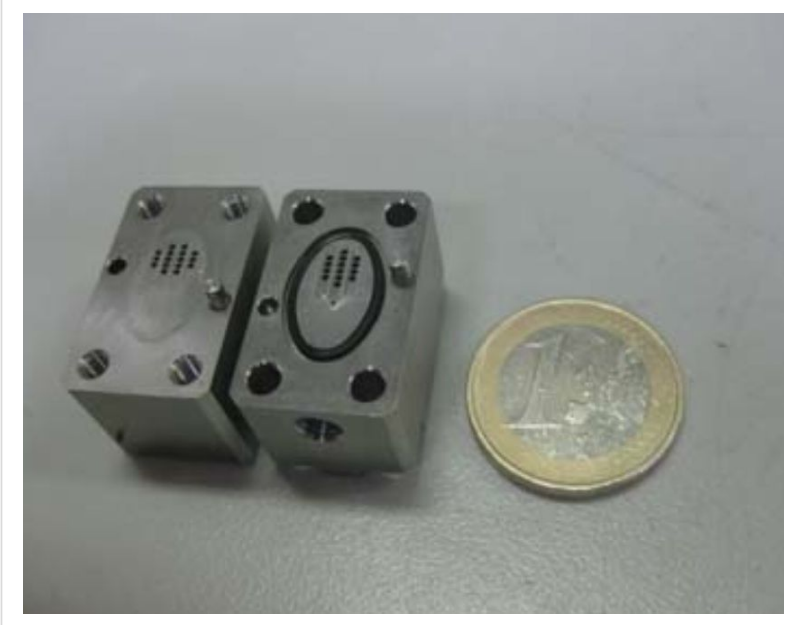

Figure 1: Hastelloy-made micromixer (MiChS $\beta-150 \mathrm{H}$ ).

1-Adamantanol (1a) dissolved in $\mathrm{HCOOH}$ (flow rate: $0.30 \mathrm{~mL} / \mathrm{min}$ ) and $98 \% \mathrm{H}_{2} \mathrm{SO}_{4}$ (flow rate: $0.88 \mathrm{~mL} / \mathrm{min}$ ) were mixed in the micromixer at room temperature, and the resulting reaction mixture was fed into the PTFE tube and then into the extraction unit, in which $\mathrm{Et}_{2} \mathrm{O}$ (flow rate: $2.5 \mathrm{~mL} / \mathrm{min}$ ) and water $(2 \mathrm{~mL} / \mathrm{min})$ were introduced to extract the carbonylation
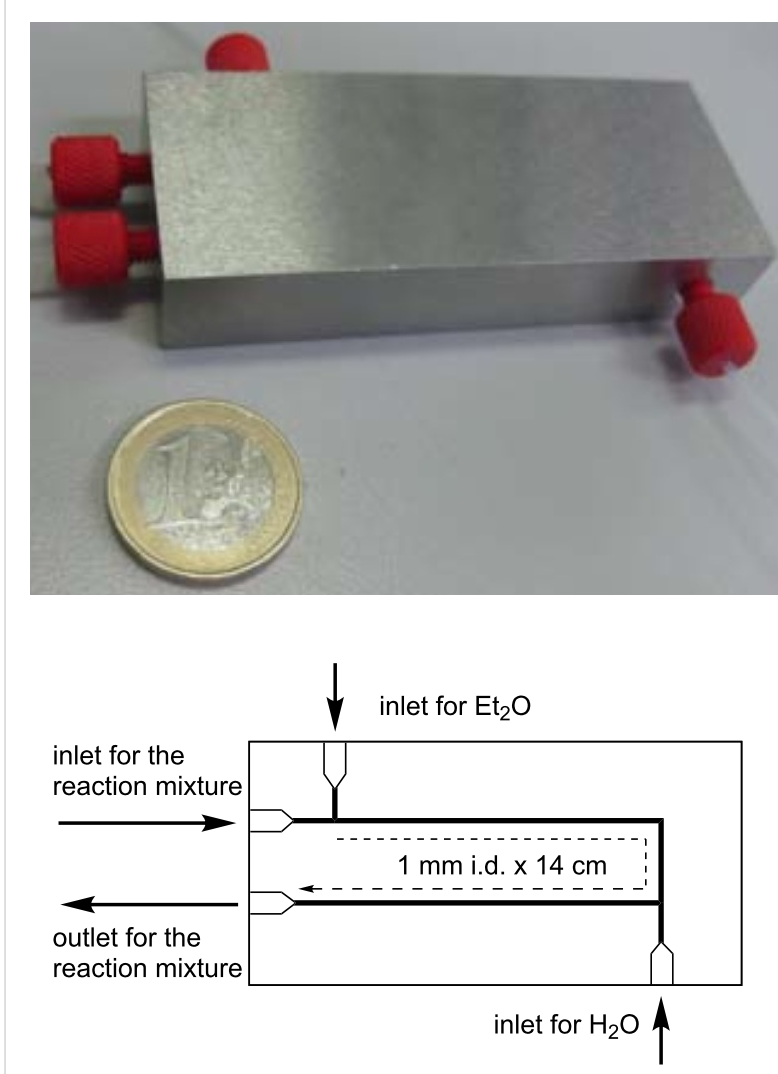

Figure 2: Hastelloy-made microextraction unit.

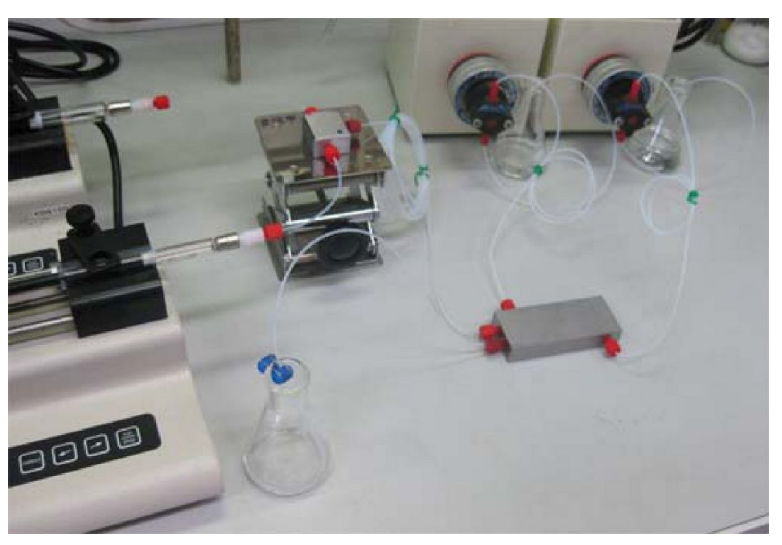

Figure 3: Acid-tolerant microflow system used for the Koch-Haaf reaction.

product and remove excess acids (Scheme 1). The biphasic mixture was collected in a flask and the ether layer was concentrated in vacuo. 1-Adamantanecarboxylic acid (2a) was obtained in $89 \%$ isolated yield after purification by silica gel column chromatography. While the residence time was a priori expected to be $2 \mathrm{~min}$ based on the total flow rate of the reagents and inner volume of the residence time unit, the observed 


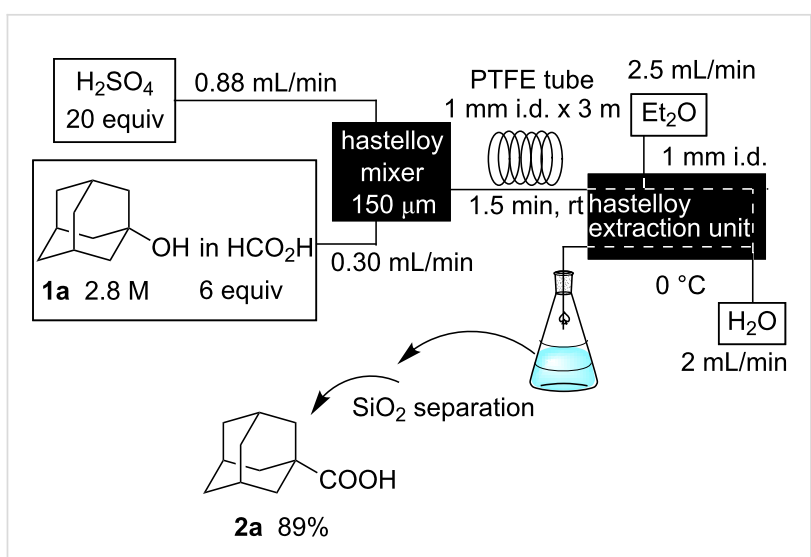

Scheme 1: Synthesis of 1-adamantanecarboxylic acid (2a) in a microflow system.

residence time was $1.5 \mathrm{~min}$ due to a plug flow by the $\mathrm{CO}$ gas generated.

For comparison, we also carried out the batch reaction in a $50 \mathrm{~mL}$ glass flask on $4 \mathrm{mmol}$ scale to give $\mathbf{2 a}$ in $92 \%$ yield. In the batch reaction, the careful addition of a solution of $\mathbf{1 a}$ in formic acid over a period of $5 \mathrm{~min}$ and cooling in an ice bath were necessary to achieve good results. Indeed, without a cooling bath, we observed that the temperature of the reaction mixture rose up to $50-60{ }^{\circ} \mathrm{C}$. It is therefore remarkable that the reaction in the microflow system can be performed successfully at room temperature without any cooling unit.

We then investigated the reaction of some other adamantanols, such as that of 2-adamantanol (1b) and 2-methyl-2-adamantanol (1c) (Scheme 2). The reaction of $\mathbf{1 b}$ in a microflow system gave a mixture of 2-adamantanecarboxylic acid (2b) and 1 -adamantanecarboxylic acid (2a) (82\% total yield, $\mathbf{2 b}: \mathbf{2 a}=$ $58: 42$ ), in which the latter compound originated from the isomerized tertiary cation, which derived from the initially formed secondary cation. The batch reaction gave a mixture of 2b and 2a in $65 \%$ total yield with a greater proportion of the rearranged product $(\mathbf{2} \mathbf{b}: \mathbf{2 a}=14: 86)$. The reaction of 2-methyl2 -adamantanol (1c) resulted in a mixture of the carboxylated products, $\mathbf{2 c}, \mathbf{2} \mathbf{c}^{\prime}$, and $\mathbf{2} \mathbf{c}^{\prime \prime}$ in $97 \%$ total yield $\left(\mathbf{2 c}: \mathbf{2} \mathbf{c}^{\prime}: \mathbf{2} \mathbf{c}^{\prime \prime}=\right.$ 23:53:24). The batch reaction resulted in an inferior yield with more of the rearranged products ( $83 \%$ yield, $\mathbf{2 c}: \mathbf{2} \mathbf{c}^{\prime}: \mathbf{2} \mathbf{c}^{\prime \prime}=$ 19:62:19). All results are summarized in Table 1.

Multigram scale synthesis of 2a from 1a was carried out in a continuous flow reaction. When the reaction of $\mathbf{1 a}(45 \mathrm{mmol})$ was performed for $55 \mathrm{~min}, 7.1 \mathrm{~g}$ of $\mathbf{2 a}$ was obtained in $88 \%$ yield, demonstrating that the present microflow system can be used for multigram scale synthesis without any problems (Scheme 3).
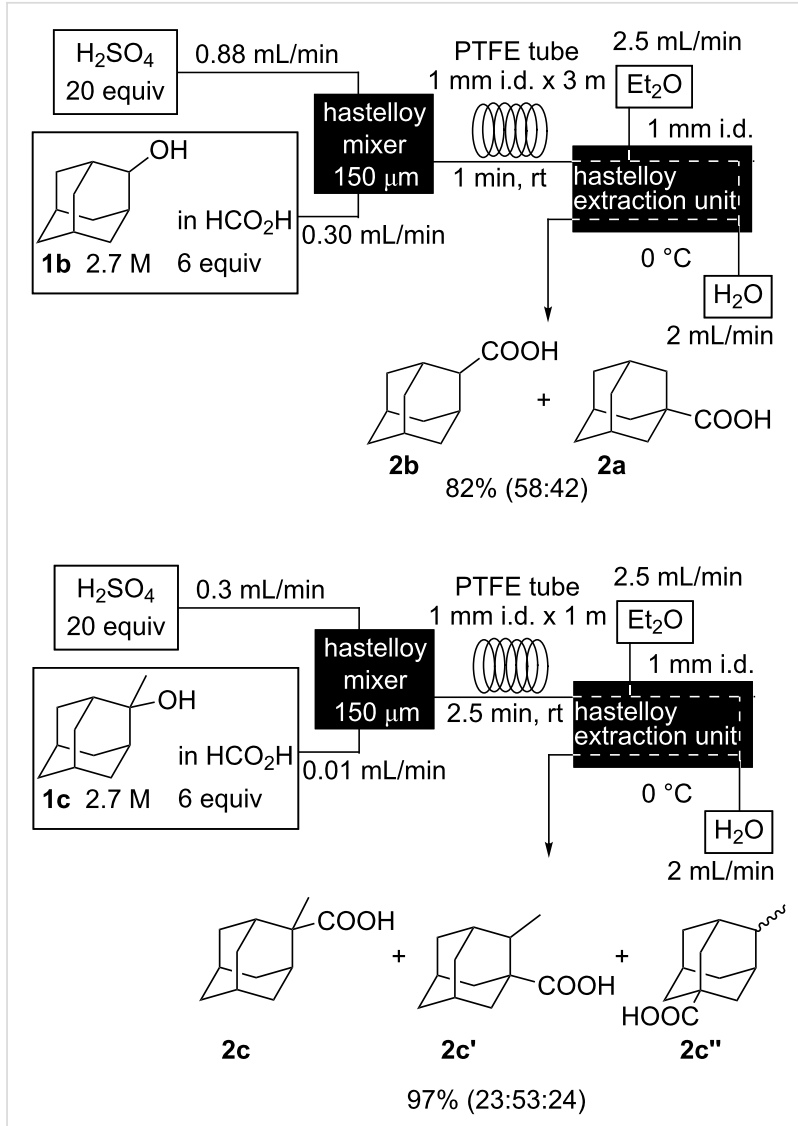

Scheme 2: Koch-Haaf reaction of $\mathbf{1 b}$ and $1 \mathrm{c}$ in a microflow system.

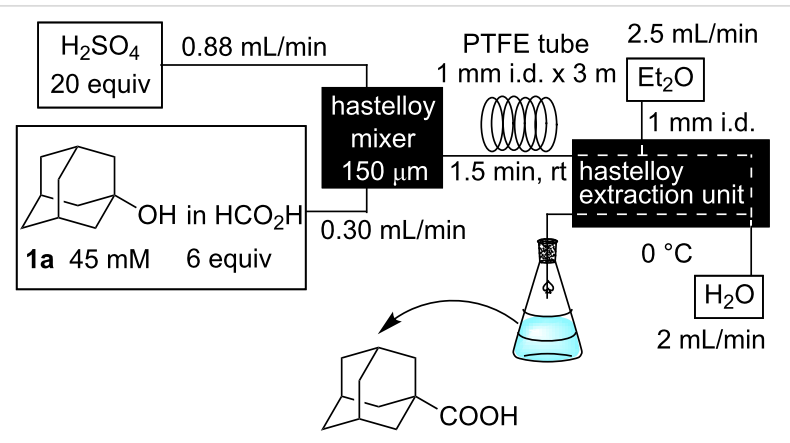

2a $7.1 \mathrm{~g}(88 \%)$

operation time: $55 \mathrm{~min}$

Scheme 3: Multigram scale flow synthesis of 1-adamantanecarboxylic acid $(2 a)$.

\section{Conclusion}

In this work, we demonstrated that the Koch-Haaf reaction of adamantanols was successfully carried out in an acid-tolerant microflow system comprising a hastelloy-made micromixer, a PTFE tube, and a hastelloy-made microextraction unit. Unlike in the batch system, the reaction could be carried out at room temperature without any cooling equipment. The employed reaction-to-workup system was useful for the multigram scale 


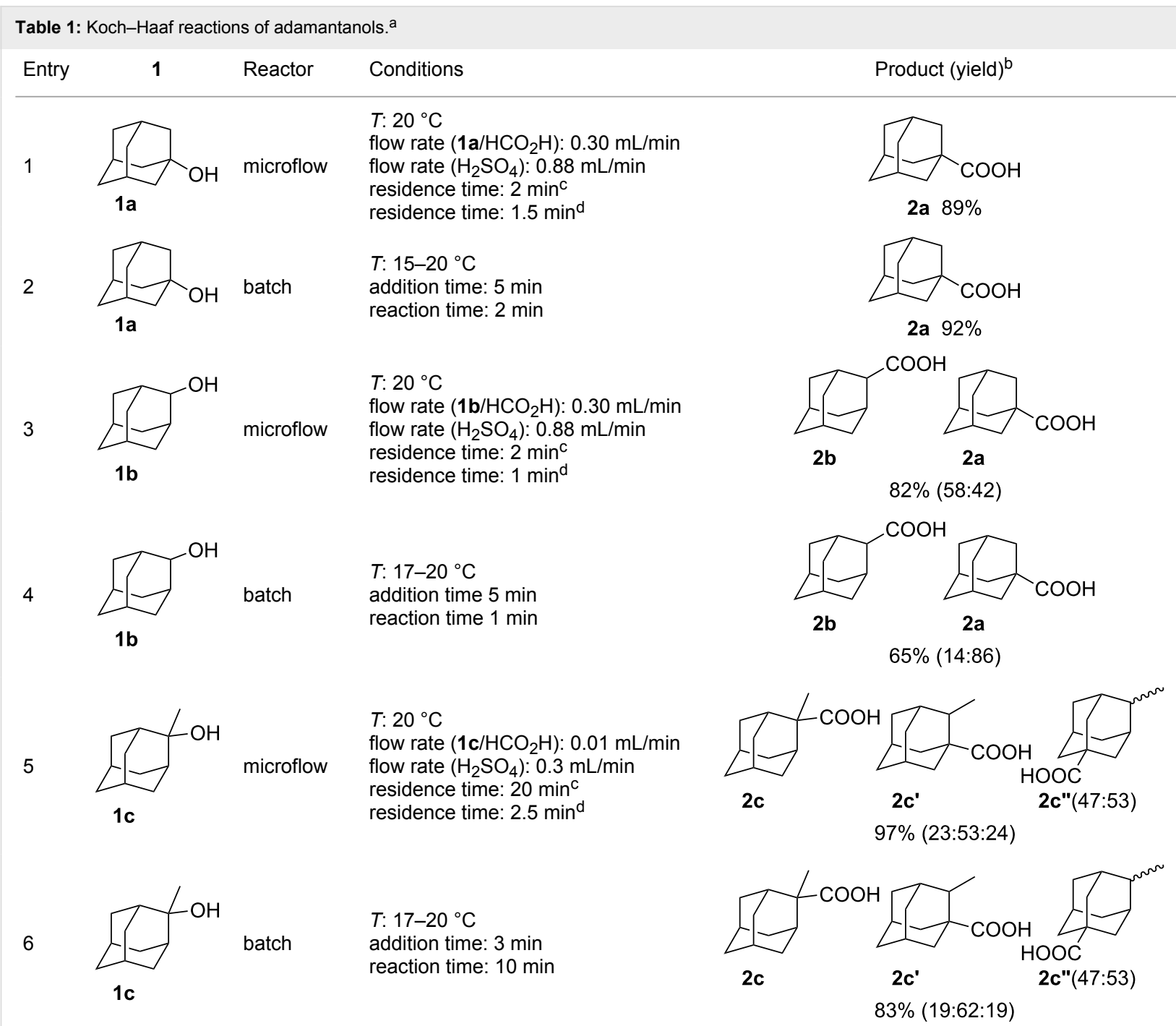

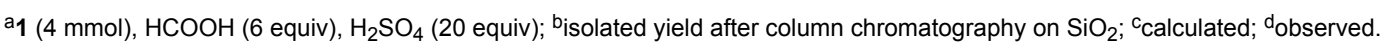

synthesis of 1-adamantanecarboxylic acid (2a). We are now expanding the system to other cationic systems and the results will be published in due course.

\section{Experimental}

Typical procedure for Koch-Haaf reaction in a microflow system. Multigram scale synthesis of 1-adamantanecarboxylic acid (2a). 1-Adamantanol (1a, $60 \mathrm{mmol}, 9.2 \mathrm{~g}$ ) was dissolved in $96 \% \mathrm{HCOOH}$ (360 mmol, $16.6 \mathrm{~g}$ ), and the solution was placed in a $50 \mathrm{~mL}$ syringe $(22.3 \mathrm{~mL})$, which was then attached to a syringe pump. Concentrated $\mathrm{H}_{2} \mathrm{SO}_{4}(99 \%)$ $(1.2 \mathrm{~mol}, 64 \mathrm{~mL})$ was placed in $100 \mathrm{~mL}$ syringe. These liquids were mixed in the hastelloy micromixer $(150 \mu \mathrm{m})$ (flow rate: 1a in $\left.\mathrm{HCOOH}=0.3 \mathrm{~mL} / \mathrm{min}, \mathrm{H}_{2} \mathrm{SO}_{4}=0.88 \mathrm{~mL} / \mathrm{min}\right)$. The resulting reaction mixture was then fed into the residence time unit (PTFE tube, $1 \mathrm{~mm}$ i.d. $\times 3 \mathrm{~m}$ ). The residence time was observed to be $1.5 \mathrm{~min}$. The mixture of products was fed into the hastelloy-made extraction unit, which was cooled by an ice/ water bath. $\mathrm{Et}_{2} \mathrm{O}(2.5 \mathrm{~mL} / \mathrm{min})$ and water $(2 \mathrm{~mL} / \mathrm{min})$ were fed into the extraction unit. The mixture that was eluted during the first 5 min was discarded and the portion that followed was collected for $55 \mathrm{~min}$ (1a: $45 \mathrm{mmol}$ ). The ethereal layer was separated, and washed with $1.4 \mathrm{~N} \mathrm{KOH}$ aq. The aqueous layer was acidified with $1 \mathrm{~N} \mathrm{HCl}$ and extracted with $\mathrm{Et}_{2} \mathrm{O}$. The organic layer was dried over $\mathrm{MgSO}_{4}$, filtered, and evaporated. 1-Adamantanecarboxylic acid (2a) was obtained in $88 \%$ yield as a white solid $\left(7.1 \mathrm{~g}, \mathrm{mp} 171-172{ }^{\circ} \mathrm{C}\right)$. The obtained product was identified by comparison of the ${ }^{1} \mathrm{H}$ NMR and ${ }^{13} \mathrm{C}$ NMR spectra with those of commercially available authentic samples. All other products, $\mathbf{2 b}, \mathbf{2 c}, \mathbf{2} \mathbf{c}^{\prime}$, and $\mathbf{2} \mathbf{c}^{\prime \prime}$ were identified by means of NMR spectroscopy by comparison with literature data $[32,33]$. 


\section{Typical procedure for Koch-Haaf reaction in a batch reaction system}

In a $50 \mathrm{~mL}$ two-necked round bottom flask, $99 \% \mathrm{H}_{2} \mathrm{SO}_{4}$ ( $80 \mathrm{mmol}, 7.85 \mathrm{~g})$ was placed. A solution of 1-adamantanol (1a, $4 \mathrm{mmol}, 613 \mathrm{mg})$ in $96 \% \mathrm{HCOOH}(24 \mathrm{mmol}, 1.01 \mathrm{~g})$ was added through a dropping funnel over a period of $5 \mathrm{~min}$, while the temperature of the reaction mixture was maintained at $15-20{ }^{\circ} \mathrm{C}$ in an ice/water bath. The reaction mixture was stirred at $15-20{ }^{\circ} \mathrm{C}$ for an additional $2 \mathrm{~min}$, poured into ice/water and extracted with $\mathrm{Et}_{2} \mathrm{O}$. The ethereal layer was washed with $1.4 \mathrm{~N}$ $\mathrm{KOH}$ aq, and the aqueous layer was acidified with $1 \mathrm{~N} \mathrm{HCl}$ and extracted with $\mathrm{Et}_{2} \mathrm{O}$. The organic layer was dried over $\mathrm{MgSO}_{4}$ evaporated and purified by column chromatography on $\mathrm{SiO}_{2}$. Compound 2a was obtained in $92 \%$ yield $(667 \mathrm{mg})$. The reaction of $\mathbf{1 b}$ and $\mathbf{1 c}$ was carried out by a similar procedure.

\section{Acknowledgements}

The authors thank MCPT and NEDO for financial support of this work. IR acknowledges the Grant-in-Aid for Scientific Research on Innovative Areas (No. 2105) from the MEXT Japan for funding.

\section{References}

1. Wirth, T., Ed. Microreactors in Organic Synthesis and Catalysis; Wiley-VCH: Weinheim, Germany, 2008. doi:10.1002/9783527622856

2. Hessel, V.; Renken, A.; Schouten, J. C.; Yoshida, J. Micro Process Engineering; Wiley-VCH: Weinheim, Germany, 2009.

3. Mason, B. P.; Price, K. E.; Steinbacher, J. L.; Bogdan, A. R.; McQuade, D. T. Chem. Rev. 2007, 107, 2300-2318. doi:10.1021/cr050944c

4. Yoshida, J.; Nagaki, A.; Yamada, T. Chem.-Eur. J. 2008, 14, 7450-7459. doi:10.1002/chem.200800582

5. Lin, W.-Y.; Wang, Y.; Wang, S.; Tseng, H.-R. Nano Today 2009, 4, 470-481. doi:10.1016/j.nantod.2009.10.007

6. McMullen, J. P.; Jensen, K. F. Annu. Rev. Anal. Chem. 2010, 3, 19-42. doi:10.1146/annurev.anchem.111808.073718

7. Webb, D.; Jamison, T. F. Chem. Sci. 2010, 1, 675-680. doi:10.1039/C0SC00381F

8. Yoshida, J. Chem. Rec. 2010, 10, 332-341. doi:10.1002/tcr.201000020

9. Wegner, J.; Ceylan, S.; Kirschning, A. Chem. Commun. 2011, 47, 4583-4592. doi:10.1039/c0cc05060a

10. Fukuyama, T.; Rahman, M. T.; Sato, M.; Ryu, I. Synlett 2008, 151-163. doi:10.1055/s-2007-1000884

11. Fukuyama, T.; Shinmen, M.; Nishitani, S.; Sato, M.; Ryu, I. Org. Lett. 2002, 4, 1691-1694. doi:10.1021/ol0257732

12. Liu, S.; Fukuyama, T.; Sato, M.; Ryu, I. Org. Process Res. Dev. 2004, 8, 477-481. doi:10.1021/op034200h

13. Rahman, M. T.; Fukuyama, T.; Kamata, N.; Sato, M.; Ryu, I. Chem. Commun. 2006, 2236-2238. doi:10.1039/B600970K

14. Fukuyama, T.; Kobayashi, M.; Rahman, M. T.; Kamata, N.; Ryu, I. Org. Lett. 2008, 10, 533-536. doi:10.1021/ol702718z

15. Wienhöfer, I. C.; Studer, A.; Rahman, M. T.; Fukuyama, T.; Ryu, I. Org. Lett. 2009, 11, 2457-2460. doi:10.1021/ol900713d

16. Fukuyama, T.; Rahman, M. T.; Kamata, N.; Ryu, I. Beilstein J. Org. Chem. 2009, 5, No. 34. doi:10.3762/bjoc.5.34
17. Fukuyama, T.; Hino, Y.; Kamata, N.; Ryu, I. Chem. Lett. 2004, 33, 1430-1431. doi:10.1246/cl.2004.1430

18. Sugimoto, A.; Sumino, Y.; Takagi, M.; Fukuyama, T.; Ryu, I. Tetrahedron Lett. 2006, 47, 6197-6200. doi:10.1016/j.tetlet.2006.06.153

19. Sugimoto, A.; Fukuyama, T.; Sumino, Y.; Takagi, M.; Ryu, I. Tetrahedron 2009, 65, 1593-1598. doi:10.1016/j.tet.2008.12.063

20. Matsubara, H.; Hino, Y.; Tokizane, M.; Ryu, I. Chem. Eng. J. 2011, 167, 567-571. doi:10.1016/j.cej.2010.08.086

21. Tsutsumi, K.; Terao, K.; Yamaguchi, H.; Yoshimura, S.; Morimoto, T.; Kakiuchi, K.; Fukuyama, T.; Ryu, I. Chem. Lett. 2010, 39, 828-829. doi:10.1246/cl.2010.828

22. Suga, S.; Nagaki, A.; Yoshida, J. Chem. Commun. 2003, 354-355. doi:10.1039/B211433J

For Friedel-Crafts alkylation with carbocation intermediates using a microreator.

23. Tanaka, K.; Motomatsu, S.; Koyama, K.; Tanaka, S.; Fukase, K. Org. Lett. 2007, 9, 299-302. doi:10.1021/ol062777o For acid-catalyzed dehydration of alcohols via carbocation intermediates in a mircoflow system.

24. Brandt, J. C.; Elmore, S. C.; Robinson, R. I.; Wirth, T. Synlett 2010, 3099-3103. doi:10.1055/s-0030-1259075 For Ritter reaction in a microflow system.

25. Koch, H.; Haaf, W. Justus Liebigs Ann. Chem. 1958, 618, 251-266. doi:10.1002/jlac.19586180127

26. Hoffmann-Emery, F.; Hilpert, H.; Scalone, M.; Waldmeier, P. J. Org. Chem. 2006, 71, 2000-2008. doi:10.1021/jo0523666

27. Sorensen, B.; Rohde, J.; Wang, J.; Fung, S.; Monzon, K.; Chiou, W.; Pan, L.; Deng, X.; Stolarik, D.; Frevert, E. U.; Jacobson, P.; Link, J. T. Bioorg. Med. Chem. Lett. 2006, 16, 5958-5962. doi:10.1016/j.bmcl.2006.08.129

28. Becker, C. L.; Engstrom, K. M.; Kerdesky, F. A.; Tolle, J. C.; Wagaw, S. H.; Wang, W. Org. Process Res. Dev. 2008, 12, 1114-1118. doi:10.1021/op800065q

29. Wan, Z.; Laine, D. I.; Yan, H.; Zhu, C.; Widdowson, K. L.; Buckley, P. T.; Burman, M.; Foley, J. J.; Sarau, H. M.; Schmidt, D. B.; Webb, E. F.; Belmonte, K. E.; Palovich, M. Bioorg. Med. Chem. Lett. 2009, 19, 4560-4562. doi:10.1016/j.bmcl.2009.07.006

30. Barton, V.; Ward, S. A.; Chadwick, J.; Hill, A.; O'Neill, P. M. J. Med. Chem. 2010, 53, 4555-4559. doi:10.1021/jm100201j

31. Shmailov, A.; Alimbarova, L.; Shokova, E.; Tafeenko, V.; Vatsouro, I.; Kovalev, V. Tetrahedron 2010, 66, 3058-3064. doi:10.1016/j.tet.2010.02.043

32. Mukherjee, A.; Wu, Q.; le Noble, W. J. J. Org. Chem. 1994, 59, 3270-3274. doi:10.1021/jo00091a010

33. Alford, J. R.; Cuddy, B. D.; Grant, D.; McKervey, M. A. J. Chem. Soc., Perkin Trans. 1 1972, 2707-2713. doi:10.1039/P19720002707 


\section{License and Terms}

This is an Open Access article under the terms of the Creative Commons Attribution License

(http://creativecommons.org/licenses/by/2.0), which permits unrestricted use, distribution, and reproduction in any medium, provided the original work is properly cited.

The license is subject to the Beilstein Journal of Organic Chemistry terms and conditions:

(http://www.beilstein-journals.org/bjoc)

The definitive version of this article is the electronic one which can be found at:

doi:10.3762/bjoc.7.149 